
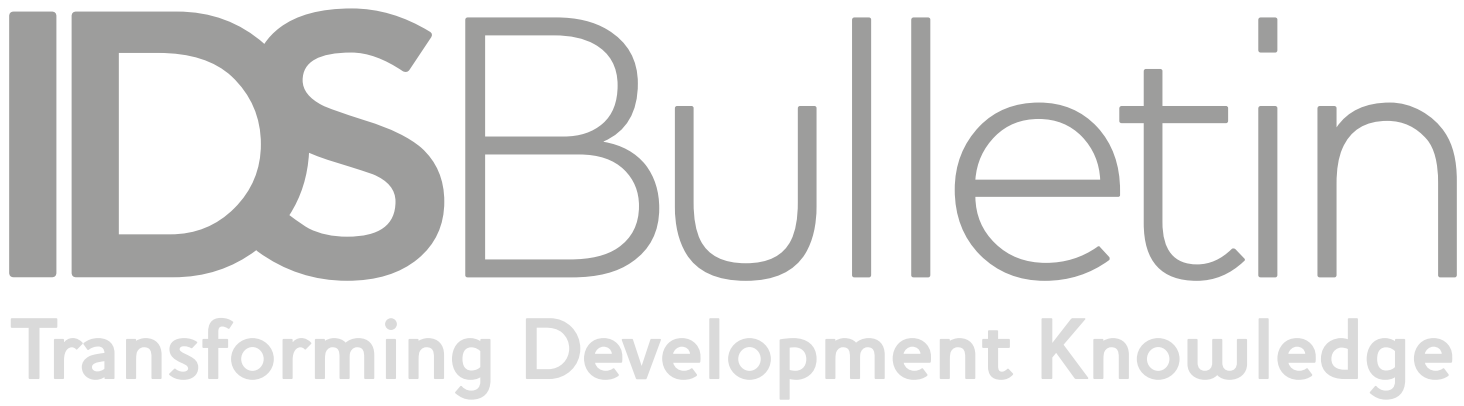

Development Knowledge

Volume 48 | Number 4 | July 2017

\title{
COURTING CATASTROPHE? HUMANITARIAN POLICY AND PRACTICE IN A CHANGING CLIMATE
}

Editors Siri Eriksen, Lars Otto Naess, Ruth Haug, Aditi Bhonagiri and Lutgart Lenaerts

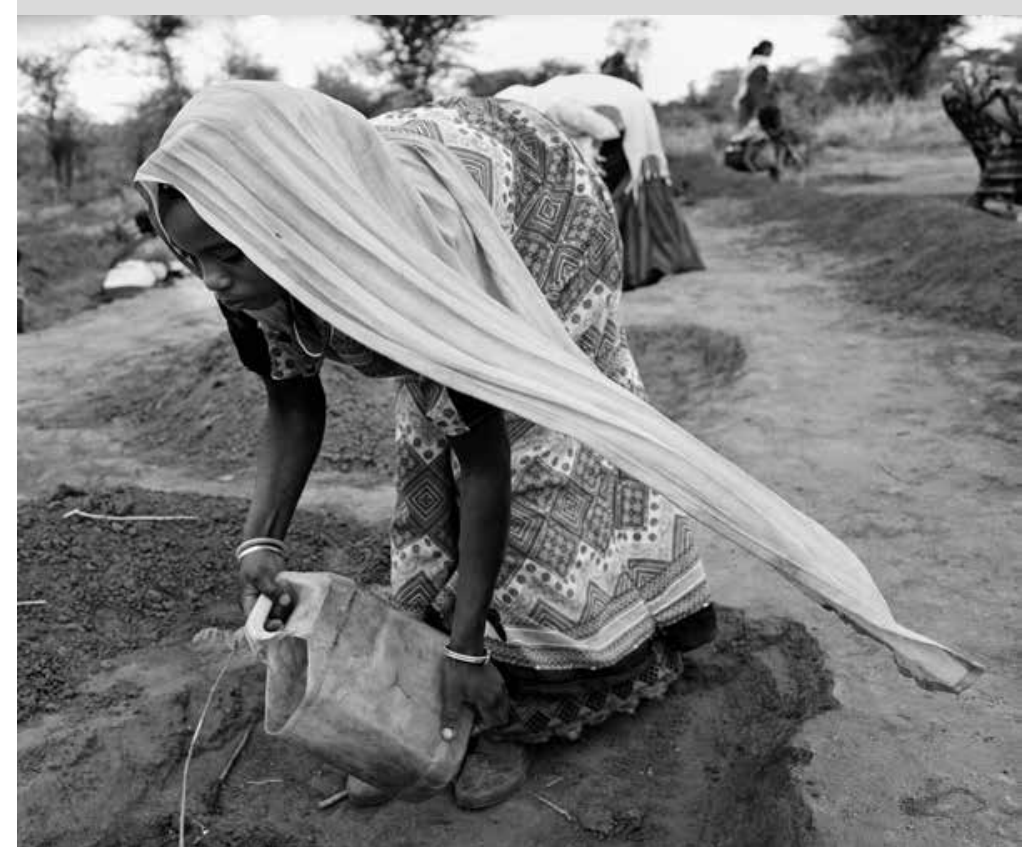


Notes on Contributors

Introduction: Courting Catastrophe? Can Humanitarian Actions Contribute to Climate Change Adaptation?

Siri Eriksen, Lars Otto Naess, Ruth Haug, Lutgart Lenaerts and Aditi Bhonagiri

Climate Change Adaptation Through Humanitarian Aid? Promises, Perils and Potentials of the 'New Humanitarianism'

Andrei Marin and Lars Otto Naess

Scalable and Sustainable: How to Build Anticipatory Capacity into Social Protection Systems

Cecilia Costella, Catalina Jaime, Julie Arrighi, Erin Coughlan de Perez, Pablo Suarez and Maarten van Aalst

Climate Change and Disasters: Institutional Complexities and Actors' Priorities for Mitigation, Adaptation and Response

Bahadar Nawab and Ingrid Nyborg

Social Vulnerability and Local Adaptation in Humanitarian Response: The Case of Pakistan

Ingrid Nyborg and Bahadar Nawab

The Power of 'Know-Who': Adaptation to Climate Change in a Changing Humanitarian Landscape in Isiolo, Kenya

Marianne Mosberg, Elvin Nyukuri and Lars Otto Naess

Social Protection or Humanitarian Assistance: Contested Input Subsidies and Climate Adaptation in Malawi

Ruth Haug and Bjørn K.G. Wold

Rethinking Food Aid in a Chronically Food-Insecure Region: Effects of Food Aid on Local Power Relations and Vulnerability Patterns in Northwestern Nepal Sigrid Nagoda

What Does Climate Change Adaptation Mean for Humanitarian Assistance? Guiding Principles for Policymakers and Practitioners

Sigrid Nagoda, Siri Eriksen and Øivind Hetland

Glossary 


\title{
What Does Climate Change Adaptation Mean for Humanitarian Assistance? Guiding Principles for Policymakers and Practitioners
}

\author{
Sigrid Nagoda, ${ }^{1}$ Siri Eriksen ${ }^{2}$ and Øivind Hetland ${ }^{3}$
}

\begin{abstract}
Vulnerability to climate change is the result of complex interactions of various social, political, economic and environmental conditions. Humanitarian actions, while often having short-term and 'neutral' intentions, necessarily influence the development pathways that define people's vulnerability to climate change. On the one hand, humanitarian interventions risk reinforcing existing vulnerability patterns by increasing the gap between those who benefit from different programmes and those that remain marginalised. On the other, addressing climate change may provide new opportunities for transforming the development pathways that create vulnerability in the first place. However, while there are shifts at the policy level towards integrating humanitarian assistance with longer-term development, considerations about how humanitarian action may support transformational adaptation are often missing. This article describes a framework for integrating climate change adaptation concerns into humanitarian policies and actions, which has been developed in collaboration with several humanitarian organisations to support efforts to reduce longer-term vulnerability and the recurrence of humanitarian crises.
\end{abstract}

Keywords: humanitarian assistance, climate change adaptation, vulnerability, transformational change, guidelines, policy processes.

\section{Introduction}

Humanitarian assistance and climate change adaptation are often regarded as two separate disciplines in practice as well as in academia. They are often carried out by different actors, governed through different policies, funded through different mechanisms, and have different goals. However, while the main objective of humanitarian assistance is - and must be - to save lives and alleviate immediate suffering, it makes a lot of sense to do so in a way that reduces longer-term vulnerability and the recurrence of humanitarian crises. Indeed, the humanitarian sector is already moving to integrate longer-term approaches such as 
social protection (Haug and Wold; Costello et al. and Marin and Naess, this IDS Bulletin), disaster risk reduction and disaster preparedness as well as through the resilience agenda (see, for example, IFRC 2016a; Jeans, Thomas and Castillo 2016). However, while there are shifts at the policy level towards integrating humanitarian assistance with longerterm development, considerations about how humanitarian action may support transformational climate change adaptation are often missing.

As outlined by Eriksen et al. (this IDS Bulletin), climate change intersects with humanitarian crises and how they are handled in four main ways: first, many disasters are climate-related; second, climate change may contribute to social changes that influence the nature of humanitarian crises (also non-climatic crises); third, how a non-climatic disaster is handled is critical for how vulnerable a community may be to future climate events; and fourth, humanitarian aid can either support or undermine transformations towards climate-resilient development pathways (development trajectories that combine mitigation of emissions, equitable development and reduced vulnerability; see also Eriksen et al., introduction to this IDS Bulletin). Hence, how we design and implement humanitarian interventions have an impact - sometimes a substantial impact - on future vulnerability to climate change. This calls for approaches to reduce climate vulnerability as part of the humanitarian response in order to prevent and address the growing number of protracted crises and ultimately address the underlying causes for vulnerability.

However, the challenge is not merely to make shorter-term measures long term, it is also about transforming the nature of the measures and the way that they are carried out so that they open up space for multiple vulnerability knowledges and alternative development pathways (Eriksen et al., this IDS Bulletin). What constitutes opportunities to support potential transformational adaptation (adaptation that changes the fundamental attributes of a system in response to climate and its effects as opposed to incremental adjustments - IPCG 2014) is context specific: First, vulnerability is dependent on social, political, economic and environmental changes as well as inequitable social and power relations generating vulnerability for a group or individual at a particular point in time and space. Second, the way that a humanitarian organisation interacts with donors and other development actors frames what actions are possible within a particular vulnerability context. Third, what might constitute more climate-resilient development pathways - as well as the political spaces for challenging current pathways - varies between contexts. Hence there is no 'blueprint' for 'good adaptation' in humanitarian actions. What may make sense in one context may not be practically possible or may even exacerbate vulnerability in another (Eriksen et al. 2011 ). Instead, humanitarian organisations require a framework for analysing the vulnerability and institutional contexts in which they work in order to reflect on what 'good adaptation' may be for whom and in which contexts, and identify the practical spaces for altering practices within current planning and 
implementation. Such a framework should also assist organisations to interrogate the assumptions regarding vulnerability and development that underlie their work, as well as to help them reflect upon whether or not there is a need to rethink the way that they operate.

In this article, we describe the development of key principles aimed at providing such a framework for analysis and reflection that are further described in Eriksen et al. (forthcoming). Importantly, these principles do not provide a 'blueprint' nor aim to replace the great number of guidelines in support of climate change adaptation currently used by humanitarian and development organisations. Rather, they aim to help organisations understand how their existing approaches and guidelines link to climate change adaptation, recognise where gaps or contradictions exist, and identify opportunities (and limitations) for humanitarian interventions to help drive transformative types of adaptation.

The development of these guiding principles formed an important part of the project 'Courting Catastrophe? Humanitarian Policy and Practice in a Changing Climate' (2012-16). The project involved seven case studies of different humanitarian approaches in various geographic and institutional contexts, including in Nepal, Pakistan, Bangladesh, Ethiopia, Kenya, Malawi and Zambia. In particular, the guiding principles are a result of discussions with practitioners and policymakers, feedback on presentations of research findings at conferences and seminars, as well as interviews with the representatives of various humanitarian organisations.

In the following section, we describe the conceptual underpinnings of transformational adaptation, and what it means for humanitarian approaches and their role in development in a broader sense. In Section 3 we describe how key findings from across the Courting Catastrophe case studies form a starting point for developing guiding principles within this conceptual framework. In Section 4, we use the normative principles of sustainable adaptation to frame the guiding principles for how humanitarian interventions can support transformative adaptation. Drawing on findings from the case studies, we highlight key questions and practical entry points relevant to each principle.

\section{Humanitarian aid in the context of transformational adaptation}

Disaster and crisis of current systems can represent an opportunity for dramatic changes and transformation. However, they can also represent an opportunity for vested interests and entrenched power structures to yield their agency and get their interests/actions implemented without critical resistance because of the urgency and institutional crisis due to disaster. Humanitarian lifesaving actions, while they often have short-term objectives, necessarily form part of the actions that comprise development pathways, as they risk reinforcing or altering practices, social structures and norms. A critical question to ask in this regard is under what conditions or through which modalities/approaches do humanitarian actions contribute to either transformation or entrenchment? 
Transformative change can be generally represented through three interacting spheres of transformation, referred to as the practical, political, and personal spheres (O'Brien and Sygna 2013). These spheres capture the ways that beliefs, values and worldviews interact with political decision-making and governance, as well as with on-the-ground practices that contribute to sustainable systems. According to O'Brien $e t$ al. (2015), transformation in practice is contingent on a political sphere, which includes the systems and structures that create the rules, norms and incentives for different types of behaviours and practices. These in turn are influenced by subjective views of systems and relationships that are represented in a personal sphere. Indeed, individual and shared beliefs, values and worldviews often drive political priorities and goals and influence framings of problems and solutions, which can lead to conflicts and tensions in decision-making processes that often impede transformative change.

While there are shifts at the international policy level towards integrating humanitarian assistance with longer-term development and to integrate longer-term perspectives into humanitarian assistance, this shift seldom explicitly considers the transformational potential of humanitarian aid in a climate change context. Humanitarian assistance is generally accepted to mean the aid and action designed to save lives, alleviate suffering, and maintain and protect human dignity during and in the aftermath of man-made crises and natural disasters, as well as to strengthen preparedness for and prevent the occurrence of such situations (Good Humanitarian Donorship 2017). What marks it out from other forms of aid and foreign assistance is that it should be guided by the principles of:

Humanity: saving human lives and alleviating suffering wherever it is found;

Impartiality: acting solely on the basis of need, without discrimination between or within affected populations;

- Neutrality: acting without favouring any side in an armed conflict or other dispute where such action is carried out; and

Independence: the autonomy of humanitarian objectives from the political, economic, military or other objectives that any actor may hold with regard to areas where humanitarian action is being implemented.

(Global Humanitarian Assistance 2017)

The broad endorsement of the humanitarian principles by most humanitarian actors has led to the term 'humanitarian exceptionalism' as a means to distinguish humanitarian actions from interventions that may have political and security objectives (Bennett, Foley and Pantuliano 2016). This distinction is particularly important for humanitarian actors that engage in conflict zones and in order to reach victims from different sides of a conflict. 
However, a strict interpretation of the humanitarian principles has also been criticised for contributing to an artificial division between humanitarian assistance and development efforts (Bennett et al. 2016). In real-life operations, it is argued, there is no linear transition or 'handover' between 'development' and 'humanitarian' interventions. Still, a range of different structures, institutions and modes of operation uphold this division, sometimes at the cost of ensuring the necessary coordination between what is regarded to be humanitarian activities on the one side and development on the other.

The need for better coordination among the wide range of humanitarian and development actors engaged in emergency situations is widely recognised. Over the last few decades, various initiatives and processes have been undertaken to improve the efficiency of the humanitarian system, including the United Nations General Assembly Resolution 46/182 in 1991, ${ }^{4}$ the establishment of the Inter-Agency Standing Committee (IASC) in 1992, the Humanitarian Reform Agenda with the Cluster Approach in 2005, ${ }^{5}$ and the IASC Transformative Agenda in 2011.

Most recently, several international events, such as the Sendai Framework for Disaster Risk Reduction, the Paris Agreement on Climate Change, and the Sustainable Development Goals agenda in 2015, and the World Humanitarian Summit (WHS) in 2016 have stressed the need for the removal of artificial barriers between short-term and longer-term interventions. An important outcome of the WHS, for example, was the Grand Bargain that aims to reform the system for humanitarian funding, simplify reporting requirement, increase support to local partners, and bridge the gap between humanitarian and development interventions.

Integrating adaptation in the humanitarian response challenges the division between development and humanitarian assistance. It obliges humanitarian actors to include the capacity, understanding and expertise from other sectors, and to plan and to implement humanitarian interventions within a longer-term horizon. Below, we outline five key ways in which humanitarian aid is directly relevant for transformation.

\section{Research approach and five key recognitions}

An examination of the seven case studies (many of which are described in separate articles in this IDS Bulletin) gleaned five common themes that are key to identifying entry points for transformative adaptation in humanitarian actions. These are:

Vulnerability is complex and its root causes are often multidimensional.

Lasting solutions to humanitarian crises require that root causes for vulnerability are identified and addressed. 
Power relations are important drivers of differential vulnerability patterns at the local level and shape policy processes and their outcomes.

Poorly designed humanitarian interventions risk enhancing local vulnerability patterns.

Preparedness and planning are key for avoiding protracted crises and ensuring early response.

\section{Vulnerability is complex and its root causes are often multidimensional}

This recognition highlights the importance of understanding vulnerability as shaped through the interactions of multiple socio-environmental processes including economic and political changes, marginalisation and inequity. Indeed, disasters and the human suffering involved are seldom caused by a climate extreme or shift in climate extreme on its own - they are the result of a combination of social and environmental factors, including for example conflict and political instability, settlement patterns, socioeconomic marginalisation, fragile institutions, and poor infrastructure and social welfare provision (O'Brien et al. 2007; Reid and Vogel 2006; Eakin and Lemos 2006; Twigg 2015). Vulnerability is dynamic, specific to each situation, and may vary greatly between individuals and groups within the same villages. The case study from Nepal, for example, shows that the most vulnerable, often women and people from low castes, would highlight oppression and social inequality as causes of their entrenched vulnerability. High caste people from the same villages, on the other hand, would point to a lack of physical infrastructure such as the absence of irrigation channels as the main reason for their climate change vulnerability (Nagoda, this IDS Bulletin). Thus, our approaches need to start with a sound understanding of the environmental, social and political factors shaping vulnerability in the particular context that we are addressing.

\section{Lasting solutions to humanitarian crises require that the root causes for vulnerability are identified and addressed}

Vulnerability to climate events manifests itself in its most extreme form in humanitarian disasters, and such disasters are often a starting point for understanding which groups are most vulnerable, and what social and environmental processes lead to their vulnerability. In many cases, humanitarian staff have a sound understanding of the local complexities creating vulnerability. Nevertheless, too often, humanitarian interventions address only the symptoms and not the root causes of a crisis, while we need to be doing both. For example, the Nepal case study demonstrates how better-off households with high-quality land close to the river may benefit much more from the construction of irrigation channels during Food for Work interventions than poor households with land in poor conditions, far from the village and too steep for irrigation (see Nagoda, this IDS Bulletin). This recognition implies that humanitarian interventions must be conceived as a part of, and contributing to, ongoing development processes and that this must be reflected in the planning 
and design of humanitarian programmes and interventions. This is a strong argument for a holistic and coordinated approach between development and humanitarian actors and programmes.

Power relations are important drivers of differential vulnerability patterns at the local level and shape policy processes and their outcomes

The third recognition underscores the importance of socio-political factors in determining local vulnerability and how these shape humanitarian interventions. In reality, most communities are heterogeneous, constituted by people and groups of people with conflicting interests, needs and ideas. Our study from Kenya, for example, shows that better-off men have more opportunities to influence local-level decision-making processes through social and political networks with local leaders and governmental representatives. The most vulnerable, on the other hand, were often marginalised in local policy spaces and did not believe in their own deliberative strategy (Mosberg et al., this IDS Bulletin). In the short term, understanding how socio-political dynamics shape local vulnerability patterns is essential for humanitarian actors to ensure that the aid benefits the most vulnerable households and individuals. In the longer term, it is necessary for designing programmes so that they can address the dynamics that determine vulnerability. Critically, humanitarian organisations and their staff form part of the power dynamics - and the production of particular vulnerability understandings and ideas of 'good development' - themselves.

\section{Poorly designed humanitarian interventions risk enhancing local vulnerability patterns}

Importantly, humanitarian interventions are never neutral as they are implemented within the frame of existing social and political structures where some people may benefit more than others. Even if do-no-harm approaches may be high on the agenda among humanitarian organisations, this recognition highlights that poorly designed interventions may nevertheless do harm by enhancing the vulnerability of already marginalised groups and individuals, and may even contribute to prolonging a humanitarian crisis. In consequence, programmes that are primarily designed to respond to acute humanitarian needs also need to take into consideration possible implications on how humanitarian interventions may influence longer-term vulnerability patterns.

\section{Preparedness and planning are key for avoiding protracted crises and} ensuring early response

With some exceptions, a crisis does not occur 'out of the blue'. Experience tells us that investing in crisis prevention and preparedness pays off, and knowledge about the local vulnerability context before the crisis hits buys time and is invaluable information when planning and designing a humanitarian response (see, for example, Haug and Wold, this IDS Bulletin). A well-designed humanitarian response that has already taken the above recognitions into account in the planning phase is more likely to address the root causes of climate vulnerability and reduce the long-term impact of the crisis. 
These five key findings have implications for what is required for humanitarian aid to be more transformative, that is, to contribute not only to longer-term measures but also to transformative adaptation. The findings underwrite the work of other studies (see, for example, IASC 2009; IFRC 2014a; Bennett et al. 2016; Jeans et al. 2016) that highlight the need for more cross-disciplinary approaches to vulnerability that allow for coordination within and between organisations rather than competition for resources. The findings also suggest the need for more financial and administrative flexibility that allow for more focus on risk reduction and preparedness as well as allocations to long-term development in the aftermath of a disaster. Crucially, they demand a better comprehension of the political economy of the country and how it influences differential vulnerability patterns at local level. Specifically, there must be a fundamental understanding that no intervention is ever neutral, in that it contributes to the political economy of development. Communities cannot be seen as homogenous - interests are diverse, there are both positive and negative effects of an intervention on different people, and people will seek to negotiate access and influence humanitarian aid to their advantage. The power to do so is greatly differentiated within a society.

\section{Guiding principles outlined}

Knowing that humanitarian operations may increase the vulnerability of some while alleviating the suffering of others suggests the need for organisations to reflect on the role that different actors have in the shaping of the vulnerability context at local, national and international level. Such reflection may be difficult when there is a need to react quickly to crises, and in the face of emergencies that are complicated, with different actors having different interests and expert skills. How can one make sense of this complexity and act to reduce rather than increase vulnerability for certain groups? Who represents the 'local' and can one link the different 'local' knowledge with expert knowledge, policy development and decision-making processes?

Several organisations have already developed guidelines that go beyond a mere hazard-based understanding of vulnerability by also taking social vulnerability into account (for example, the International Federation of Red Cross and Red Crescent Societies (IFRC 2013, 2014a, 2014b, 2016b, 2016c, 2017) and Jeans et al. (2016)). In order to take such efforts further, a framework that guides reflection on the significance of transformational adaptation in local work is required, posing new questions that help organisations interrogate the way that current practice may support or undermine climate-resilient development pathways. In this section, we use the normative principles of sustainable adaptation in order to outline guiding principles for the humanitarian sector, using the key findings described in the section above to identify entry points within planning, implementation, and evaluation of actions.

The guiding principles further described in Eriksen et al. (forthcoming) outline questions to be posed at various stages of planning, 
implementing and evaluating humanitarian interventions, using the five principles of sustainable adaptation described in Eriksen et al. (2011) and Eriksen and Marin (2011). Sustainable adaptation was selected as an approach because these are explicit normative principles developed to help adaptation efforts address poverty, inequality and environmental integrity. The terms 'adaptation' and 'sustainable', when used uncritically, can be used to conceal vested interests and avoid resistance and critical examination (Brown 2011). At the same time, the very term adaptation is problematic in terms of the tendency to depoliticise interventions and delink them from development processes (Taylor 2015). The normative principles are intended to provide very explicit criteria for identifying the positive and negative impacts of adaptation processes, helping actors within the humanitarian sector to critically examine their own measures and processes. Below, we propose some questions that can help identify opportunities for humanitarian actions to support transformational adaptation.

\section{Principle 1. Recognise the context for vulnerability, including multiple stressors (stressors other than and including climate change)}

Given that responses should be sensitive to the wider vulnerability context, including multiple stressors that contribute to vulnerability, the analysis should attempt to answer the following key questions:

What are the main reasons for being vulnerable (caste, ethnicity, gender, poverty, disability...)?

What factors other than climate change (political, social, economic and environmental) contribute to these people's vulnerability? How do these processes interact and influence people differently?

What are the historical, cultural and political processes that have shaped the vulnerability of individuals or groups?

Which interventions have been carried out before? Which projects/ programmes have been considered successful? Why and for whom?

\section{Principle 2. Acknowledge that differing values and interests affect adaptation outcomes}

Given that responses should take into account that different actors have different values and interests which may affect adaptation outcomes, the mapping should attempt to answer the following key questions:

Which are the main groups/actors with an interest in adaptation programmes and their outcomes in the region, and why?

What are the main differences in needs/interests between different groups?

- How/to what extent are the views/interests of the most vulnerable groups taken into account in national/international climate change adaptation policies and approaches? 
Principle 3. Integrate local knowledge into adaptation responses Given that successful responses need to have a conscious approach towards which knowledge is recognised and how it is used in project design and decision-making, the strategy should attempt to give answers to the following key questions:

What are the different interests and needs at local level and what are the reasons for this diversity of 'local' knowledge (also note the different conflicts and how these are negotiated at local, regional level)?

How can programmes ensure that the different types of local knowledge are integrated with other sources of knowledge when planning projects and formulating policies?

In particular, what can be done to ensure that the voices of the most vulnerable are taken into account within the formulation and the implementation of policies and programmes at both local and national levels?

Principle 4. Consider potential feedback between local and global processes Given that responses to reduce vulnerability do not happen in isolation but may directly or indirectly influence and be influenced by larger-scale processes, the strategy should attempt to give answers to the following key questions:

What are the potential effects of national and international programmes at the local level?

How do organisations work across scale? What are the other ongoing processes addressing development and adaptation in the region and how do these processes coordinate at national, regional and local level?

How can the coordination between different sectors and organisations, including between civil societies and governments at local, national and international level be strengthened?

Principle 5. Empower vulnerable groups to influence development pathways and their climate change outcomes

Given that marginalisation and social exclusion are important factors shaping vulnerability processes, the strategy should attempt to give answers to the following key questions:

Who are the most vulnerable and what are their contexts (situations) that make them vulnerable?

What are the political, economic, cultural and social processes that hinder the most vulnerable from influencing decision-making processes at local, regional and national level?

What are the opportunities that exist within the humanitarian action in question to support their active participation in influencing development pathways? 


\section{Concluding reflections: barriers and opportunities for humanitarian aid to contribute to adaptation}

Integrating adaptation concerns into humanitarian responses represents an opportunity to address humanitarian needs and at the same time reduce the risk of recurring crises. The growing recognition of the need to integrate humanitarian assistance with longer-term development has generated a number of policy recommendations for humanitarian actors, including better coordination between organisations, more focus on preparedness, better inclusion of local actors in decision-making, better understanding of the local context, and enhanced financial flexibility and transparency (see outcome of the 2016 World Humanitarian Summit). ${ }^{6}$ However, the scale and intensity of current and recurring humanitarian crises in different parts of the world suggest that much more must be done to address entrenched vulnerability patterns. Our findings show that climate change adaptation can contribute with additional insights as we take on the challenge of responding to acute humanitarian needs while simultaneously addressing longer-term vulnerability concerns and supporting more climate-resilient development pathways.

Importantly, any 'longer-term humanitarian measure' does not in itself constitute climate change adaptation. Transforming the conditions, relations and processes that cause vulnerability will often require changes in the way humanitarian interventions are planned and designed. It is how a measure is implemented in terms of reinforcing or challenging inequities and environmental change, and the extent to which it opens up space for the voices of the vulnerable - such as their vulnerability understandings and alternative conceptions of 'good development' - that determines whether outcomes are transformative or not. This implies a need for better understanding of the processes that shape local-level vulnerability patterns and a more holistic financial and administrative approach for humanitarian aid that allows organisations to address the conditions that entrench vulnerability.

This article describes the development of a framework to facilitate the application of our accumulated knowledge and best practices within climate change adaptation in humanitarian interventions. Every crisis is unique and the framework does not pretend to be a blueprint that can be applied to every situation. Rather, it proposes a set of questions, or meta guidelines, that have been formulated with the joint purpose of: (1) avoiding the risk that humanitarian actions reinforce entrenched vulnerability patterns, and (2) identifying opportunities for humanitarian actions to contribute to transformative adaptation. Importantly, the framework is not a static document, but a contribution to the continuing process of enhancing the ability of humanitarian action to alleviate human suffering in the short as well as in the long term. 


\section{Notes}

1 Department of International Environment and Development Studies (Noragric), Faculty of Landscape and Society, at the Norwegian University of Life Sciences (NMBU) (sigrid.nagoda@nmbu.no).

2 Department of International Environment and Development Studies (Noragric), Faculty of Landscape and Society, at the Norwegian University of Life Sciences (NMBU) (siri.eriksen@nmbu.no).

3 Norwegian Red Cross (oivind.hetland@redcross.no).

4 United Nations General Assembly Resolution 46/182, Strengthening of the Coordination of Humanitarian Emergency Assistance of the United Nations.

5 https://interagencystandingcommittee.org/product-categories/ cluster-approach.

6 www.worldhumanitariansummit.org/.

\section{References}

Bennett, C.; Foley, M. and Pantuliano, S. (2016) Time to Let Go: Remaking Humanitarian Action for the Modern Era, London: Humanitarian Policy Group, Overseas Development Institute (ODI)

Brown, K. (2011) 'Sustainable Adaptation: An Oxymoron?', Climate and Development 3.1: 21-31, doi:10.3763/cdev.2010.0062 (accessed 12 June 2017)

Eakin, H. and Lemos, M.C. (2006) 'Adaptation and the State: Latin America and the Challenge of Capacity-Building under Globalization', Global Environmental Change 16.1: 7-18

Eriksen, S. and Marin, A. (2011) Pastoral Pathways: Climate Change Adaptation Lessons from Ethiopia, Oslo: The Development Fund

Eriksen, S. et al. (2011) 'When Not Every Response to Climate Change is a Good One: Identifying Principles for Sustainable Adaptation', Climate and Development 3.1: 7-20

Eriksen, S.; Nagoda, S.; Mosberg, M. and Hetland, Ø. (forthcoming) 'Guiding Principles for Policymakers and Practitioners'

Global Humanitarian Assistance (2017) www.globalhumanitarianassistance.org/ data-guides/defininghumanitarian-aid/ (accessed 26 May 2017)

Good Humanitarian Donorship (2017) 23 Principles and Good Practice of Humanitarian Donorship, www.ghdinitiative.org/ghd/gns/principlesgood-practice-of-ghd/principles-good-practice-ghd.html (accessed 9 June 2017)

IASC (2009) Addressing the Humanitarian Challenges of Climate Change: Regional and National Perspectives, preliminary findings from the Inter-Agency Standing Committee regional and national level consultations, World Food Programme, International Federation of Red Cross and Red Crescent Societies and United Nations Office for the Coordination of Humanitarian Affairs

IFRC (2017) Road Map to Community Resilience. Operationalizing the Framework for Community Resilience, Geneva: International Federation of Red Cross and Red Crescent Societies 
IFRC (2016a) World Disasters Report. Resilience: Saving Lives Today, Investing for Tomorrow, Geneva: International Federation of Red Cross and Red Crescent Societies

IFRC (2016b) Applying Better Programming Initiative - Do No Harm - in a Changing Context, Geneva: International Federation of Red Cross and Red Crescent Societies

IFRC (2016c) A Red Cross Red Crescent Guide to Community Engagement and Accountability (CEA): Improving Communication, Engagement and Accountability in All We Do, pilot version, Geneva: International Federation of Red Cross and Red Crescent Societies

IFRC (2014a) IFRC Framework for Community Resilience, Geneva: International Federation of Red Cross and Red Crescent Societies

IFRC (2014b) Integrating Climate Change and Urban Risks into the VCA: Ensure Effective Participatory Analysis and Enhanced Community Action, Geneva: International Federation of Red Cross and Red Crescent Societies

IFRC (2013) IFRC Strategic Framework on Gender and Diversity Issues 2013-2020, Geneva: International Federation of Red Cross and Red Crescent Societies

IPCG (2014) Climate Change 2014: Impacts, Adaptation, and Vulnerability. Part B: Regional Aspects. Contribution of Working Group II to the Fifth Assessment Report of the Intergovernmental Panel on Climate Change, Cambridge and New York NY: Cambridge University Press

Jeans, H.; Thomas, S. and Castillo, G. (2016) The Future is a Choice: The Oxfam Framework and Guidance for Resilient Development, Oxford: Oxfam International

O'Brien, K. and Sygna, L. (2013) 'Responding to Climate Change: The Three Spheres of Transformation', Proceedings of Transformation in a Changing Climate, Oslo, Norway, University of Oslo, 19-21 June 2013

O’Brien, K.; Eriksen, S.; Inderberg, T.H. and Sygna, L. (2015) 'Climate Change and Development: Adaptation through Transformation', in T.H. Inderberg, S. Eriksen, K. O'Brien and L. Sygna (eds), Climate Change Adaptation and Development: Transforming Paradigms and Practices, London: Routledge

O’Brien, K.L.; Eriksen, S.H.; Nygaard, L. and Schjolden, A. (2007) 'Why Different Interpretations of Vulnerability Matter in Climate Change Discourses', Climate Policy 7.1: 73-88

Reid, P. and Vogel, C. (2006) 'Living and Responding to Multiple Stressors in South Africa - Glimpses from KwaZulu-Natal', Global Environmental Change 16.2: 195-206

Taylor, M. (2015) The Political Ecology of Climate Change Adaptation. Livelihoods, Agrarian Change and the Conflicts of Development, London: Routledge

Twigg, J. (2015) Disaster Risk Reduction, Good Practice Review 9, London: Overseas Development Institute (ODI) 
